\title{
In memoriam Zev Naveh (1919 Amsterdam-2011 Haifa)
}

\author{
Marc Antrop*, Teresa Pinto Correia** \\ * Ghent University, Geography Department, Krijgslaan 281 S8, B9000 Ghent, Belgium \\ ** University of Évora, ICAAM - Institute for Mediterranean Agrarian and Environmental Sciences \\ and DPAO - Department Landscape Environment and Planning Núcleo da Mitra - Apartado 94, 7002- \\ 774 Évora, Portugal
}

On the morning of March 31, 2011, at the age of 91, one of the 'founding fathers' of landscape ecology and transdisciplinary landscape science passed away. Zev Naveh was born in 1919 in Amsterdam, grew up in Germany and immigrated to Israel in 1935. There he was co-founder of the collective settlement or kibbutz Mazuba in the foothills of Western Galilee. He studied at the Hebrew University in Jerusalem, where he obtained a M.Sc. in Agronomy in 1950 and a Ph.D. in Ecology in 1960. During this time, he also worked for the Israel Ministry of Agriculture as a range and pasture researcher at the Neve Yaar Experimental Station and was a visiting research fellow at the School of Forestry at the University of California in Berkeley from 1958 to 1960 . Between 1962 and 1965 he was active as a researcher and consultant in Tanzania, Kenya and Uganda, dealing with range and pasture development. In 1965 he started his academic career at Technion, the Israel Institute of Technology in Haifa, first at the Faculty of Agricultural Engineering and from 1970-on with an additional secondary appointment at the Faculty of Architecture and Town Planning. His academic teaching covered general agronomy, systems ecology, landscape ecology, restoration ecology and vegetation engineering for biological protection and erosion control. In 1982 he founded the Ecological Garden of Technion and was its director until his retirement in 1989.

His photograph on his website at Technion carries the caption "From cowboy and shepherd to worldrenowned landscape ecologist," which summarizes rather well his life and career. In his anthology (Springer, 2007), he described how through his work at the kibbutz arose his love and interest for the Mediterranean hill and mountain landscapes, "reclaiming the rocky outcrops for cultivation" and working as a "shepherd" "and "cattle herder and breeder." Here he realized the importance of the "rich natural and cultural assets" of these landscapes and of the "very long human history of coevolution," as well as people's "utilization for good and worse."

Most of his professional career was devoted to these Mediterranean landscapes, where "the closely interwoven natural and cultural patterns and processes of these landscapes were among the major topics of my study," he wrote. His early focus was on pasture research, which brought him "naturally" to landscape ecology and restoration ecology. However, he soon broadened his scope to all landscapes, bridging the natural and social sciences with the humanities and arts, and developing basic theoretical 
concepts for the study and management of landscapes as holistic entities. Becoming increasingly aware of the global challenges and inspired by the work of Ervin Laszlo, he joined the Club of Budapest in 2004 as a Creative Member.

This evolution can clearly be seen in his publications, as in the journal Landscape and Urban Planning, where in several articles he detailed a holistic conception of landscape as a result of the interaction between nature and culture, and from this argued the need for a transdisciplinary approach to planning and management.

The publication of his book Landscape Ecology_Theory and Applications (Springer Verlag, New York, 1984) with Arthur Liebermann, was an international milestone in the development of Landscape Ecology. Again stressing the holistic nature of landscape, he introduced the Total Human Ecosystem (THE) as a model and framework for this new discipline.

After his retirement, his new mission became the education of the coming generations of landscape scientists within the perspective of a proactive, problem-oriented transdisciplinary landscape science. He channeled added enthusiasm toward those developing their work in the Mediterranean, sharing his keen grasp of the main potentials and threats to those landscapes, particularly those managed by different grazing systems. Zev's work remains an authoritative reference for all those that work and study Mediterranean landscapes.

Zev attended, always accompanied by his beloved wife Ziona, most of the international conferences, symposia and workshops of the growing science of landscape ecology. Many will remember him, always sitting in the front row, alert to all speakers and very often starting the debate with critical questions. His enthusiasm and drive were known and admired by all, in particular to the younger researchers, who he always encouraged and made clear to them the critical importance of their work. He inspired many people, and especially made those of us who are landscape scientists aware that it is our duty to contribute through our work to a better world. 